\title{
A Specific Survival Score for Patients Receiving Local Therapy for Single Brain Metastasis from a Gynecological Malignancy
}

\author{
DIRK RADES ${ }^{1}$, LIESA DZIGGEL ${ }^{1}$ and STEVEN E. SCHILD ${ }^{2}$ \\ ${ }^{1}$ Department of Radiation Oncology, University of Lübeck, Lübeck, Germany; \\ ${ }^{2}$ Department of Radiation Oncology, Mayo Clinic, Scottsdale, AZ, U.S.A.
}

\begin{abstract}
Background/Aim: Personalization of the treatment of brain metastases considering patient's overall survival (OS) prognosis is gaining importance. This study was conducted to develop an OS score particularly for patients receiving local therapies for single brain metastasis from gynecological malignancies. Patients and Methods: In 11 patients, the following factors were retrospectively analyzed for associations with OS: Age, Karnofsky performance score (KPS), tumor type, extra-cranial metastatic sites, and time from diagnosis of gynecological malignancy to treatment of brain metastasis. Factors showing at least a strong trend were used for the score. Results: A KPS of 80-90\% resulted in a significantly better OS than a KPS of 50-70\% ( $p=0.008)$. Absence of extra-cranial metastases showed a strong trend $(p=0.052)$. For the score, the following points were used: KPS $50-70 \%=0$, KPS $80-90 \%=1$, presence of extra-cranial metastatic sites $=0$, absence $=1$. Patients' scores were 0,1 or 2 points. OS rates at both 6 and 12 months were 0\%, 67\% and $100 \%$, respectively $(p=0.020)$. Conclusion: This specific score can be used to estimate OS in patients receiving local therapies for single brain metastasis from gynecological malignancies and personalize their care.
\end{abstract}

Patients with a single brain metastasis from a gynecological malignancy are quite rare and account for less than $0.5 \%$ of adult patients with brain metastases from a solid tumor (1). The majority of patients with single brain metastasis receive

This article is freely accessible online.

Correspondence to: Professor Dirk Rades, MD, Department of Radiation Oncology, University of Lübeck, Lübeck, Ratzeburger Allee 160, 23562 Lübeck, Germany. Tel: +49 45150045401, Fax: +49 45150045404, e-mail: rades.dirk@gmx.net

Key Words: Gynecological malignancies, single brain metastasis, local therapies, survival score, personalized care. a local therapy, either alone or in combination with wholebrain irradiation (WBI) plus/minus a radiation boost to the metastatic site (2). The overall survival (OS) prognoses of patients with a single brain metastasis can vary considerably between a very few months and much longer than one year. The OS prognosis should be considered when tailoring the treatment regimen to a patient. Patients with a poor expected OS time should preferably receive a short palliative regimen with consuming as little of the patients' remaining lifespan as possible. In patients with a longer expected OS time, the goals of treatment should be more on intracerebral control, prolonging of survival and avoidance of late treatmentrelated morbidities (2). Therefore, it would be very helpful if an OS score was available giving physicians a better idea of an individual patient's OS prognosis. Since solid tumors vary with respect to prognosis and biological behavior, specific OS scores for different tumor types associated with brain metastases would be ideal to choose the best personalized treatment for each patient (3-6). Furthermore, the prognoses and treatment of patients with a single brain metastasis differ from those patients with oligometastatic disease and multiple brain metastases (7-9). Therefore, specific scores for each of these three categories appear reasonable. In addition to a previous score developed in patients with brain metastases from a gynecological malignancy, of whom $80 \%$ received WBI alone and $70 \%$ had more than one lesion, this subgroup analysis was performed to create a specific OS score particularly for patients who received a local therapy for a single brain metastasis (10).

\section{Patients and Methods}

Eleven patients with a single brain metastasis from a gynecological malignancy who received a local therapy as part of their treatment between 2000 and 2016 were included in this retrospective study, which represents a subgroup analysis of a previous study (10). Local therapies included $15-25$ Gy of stereotactic radiosurgery or $3 \times 10 \mathrm{~Gy}$ of fractionated stereotactic radiotherapy alone $(N=6)$ and neurosurgical resection followed by $10 \times 3$ Gy or $20 \times 2$ Gy of whole- 
brain irradiation plus/minus a sequential boost to the resection cave $(N=5)$. Patients had either ovarian cancer $(N=8)$, cervical cancer $(N=1)$, uterine cancer $(N=1)$ or vulvar cancer $(N=1)$. In this cohort, the following factors were investigated for an association with OS: Age ( $\leq 65 v s .>65$ years, median=65), Karnofsky performance score (KPS) $(50-70 \%$ vs. $80-90 \%$, median=70), primary tumor type (ovarian cancer $v s$. other malignancies), extra-cranial metastatic sites (no vs. yes) and time from diagnosis of the gynecological malignancy to treatment of the brain metastasis ( $<36 \mathrm{vs} . \geq 36$ months, median=36). The distribution of these factors is shown in Table I.

For the statistical analyses of OS, the Kaplan-Meier method and the log-rank test were applied (11). $p$-Values from the log-rank test of $<0.05$ were considered significant, and $p$-values of $<0.06$ nearly significant (=strong trend). Factors showing at least a strong trend were used for the creation of the survival score.

\section{Results}

A KPS of $80-90 \%$ resulted in significantly better OS than a KPS of $50-70 \%(p=0.008)$. In addition, absence of extracranial metastatic sites showed a strong trend $(p=0.052)$. Therefore, these two factors were incorporated in the OS score. The OS rates at 6 and 12 months following treatment of the single brain metastasis of all investigated factors are summarized in Table II.

With respect to the OS score, the following scoring points were used: KPS of $50-70 \%=0$ points, KPS of $80-90 \%=1$ point, presence of extra-cranial metastatic sites $=0$ points, absence of extra-cranial metastatic sites $=1$ point. After adding these points, the score for a patient was either 0 $(N=4), 1(N=3)$ or $2(N=4)$ points. For these scores, the OS rates at 6 months were $0 \%, 67 \%$ and $100 \%$, respectively, and the OS rates at 12 months were also $0 \%, 67 \%$ and $100 \%$, respectively ( $p=0.020$, Figure 1$)$.

\section{Discussion}

Since patients with brain metastases from a gynaecological malignancy are rare, there is a lack of data regarding this particular group. The majority of these patients present with multiple cerebral lesions and usually receive WBI alone (2). Patients with only a single lesion often have a considerably better OS prognosis than those patients with multiple lesions and could, therefore, benefit from employment of local therapies such as neurosurgical resection and stereotactic radiosurgery/radiotherapy (2, 7-9).

Efforts have been made to improve the results of the primary treatment of gynecological malignancies including novel surgical approaches and systemic drugs (12-18). An improvement of the primary treatment often results in a better prognosis and a prolonged lifetime. Since the risk of developing metastases increases with lifetime the number of patients with brain metastases from a gynaecological malignancy will likely increase, too. For these patients,

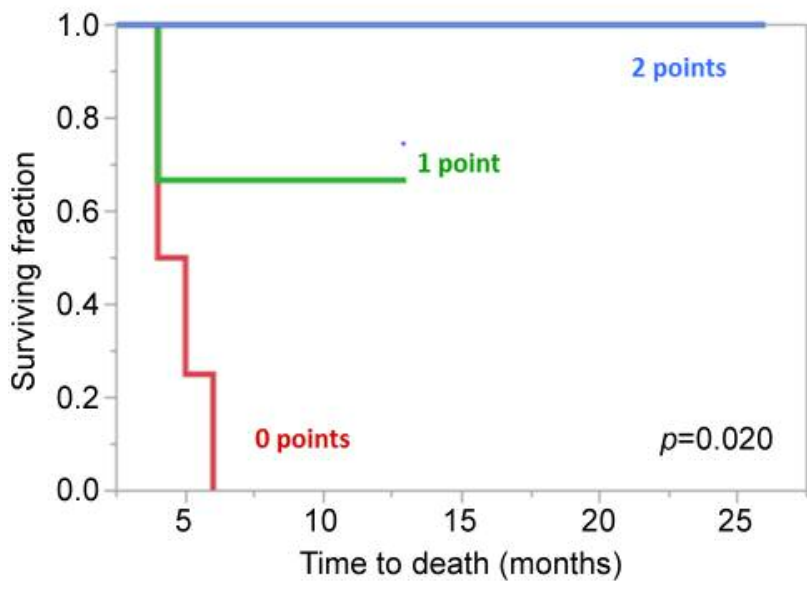

Figure 1. Kaplan-Meier curves of survival for 0, 1 and 2 scoring points. The p-value was obtained using the log-rank test.

Table I. Distribution of the factors potentially associated with survival.

Number of patients

\begin{tabular}{ll}
\hline Age at the time of treatment & \\
$\leq 65$ years & 6 \\
$>65$ years & 5 \\
Karnofsky performance score & 6 \\
$50-70 \%$ & 5 \\
$80-90 \%$ & \\
Primary tumor type & 8 \\
Ovarian cancer & 3 \\
Other malignancies & \\
Extra-cranial metastatic sites & 6 \\
No & 5 \\
Yes & \\
Time from diagnosis of the gynecological & \\
malignancy to treatment brain metastasis & 5 \\
$<36$ months & 6 \\
$\geq 36$ months &
\end{tabular}

personalized treatment regimens are required to achieve optimal results in terms of palliation, disease control and reduction of treatment-related side effects. Besides other factors, personalized treatment should also consider the patient's OS prognosis. Therefore, it would be of great value for the treating physicians to have a more precise idea of the patient's remaining lifespan. OS scores assist them with this matter (3-6). Taking into account that primary tumors are different in many aspects, specific scores should be available for different tumor types to allow best possible personalization of the treatment. Furthermore, since the treatment of brain metastases also depends on the number of lesions, i.e. one vs. limited number of vs. multiple lesions, separate OS scores for the different categories of the 
Table II. Freedom from new cerebral metatsases (univariate analysis).

\begin{tabular}{|c|c|c|c|}
\hline \multirow[t]{2}{*}{ Factor } & \multicolumn{2}{|c|}{ Survival } & \multirow[t]{2}{*}{$p$-Value } \\
\hline & At 6 months $(\%)$ & At 12 months (\%) & \\
\hline \multicolumn{4}{|c|}{ Age at the time of treatment } \\
\hline$\leq 65$ years & 50 & 50 & \\
\hline$>65$ years & 60 & 60 & 0.87 \\
\hline \multicolumn{4}{|c|}{ Karnofsky performance score } \\
\hline $50-70 \%$ & 17 & 17 & \\
\hline $80-90 \%$ & 100 & 100 & 0.008 \\
\hline \multicolumn{4}{|l|}{ Primary tumor type } \\
\hline Ovarian cancer & 50 & 50 & \\
\hline Other malignancies & 67 & 67 & 0.70 \\
\hline \multicolumn{4}{|c|}{ Extra-cranial metastatic sites } \\
\hline No & 83 & 83 & \\
\hline Yes & 20 & n.a & 0.052 \\
\hline \multicolumn{4}{|c|}{$\begin{array}{l}\text { Time from diagnosis of the gynecological } \\
\text { malignancy to treatment brain metastasis }\end{array}$} \\
\hline$<36$ months & 40 & 40 & \\
\hline$\geq 36$ months & 67 & 67 & 0.42 \\
\hline
\end{tabular}

n-a-: Not available; bold $p$-values=significant or nearly significant.

numbers of lesions would be desirable $(2,7-9)$. The present study aimed to create an OS score specifically for patients treated with local therapies for a single brain metastasis from a gynaecological malignancy. This study represents a subgroup analysis of a previous study that included patients with gynecological malignancies who belonged to all three categories regarding the number of brain metastases (one lesion, limited number of lesions, multiple lesions) (10). Moreover, $80 \%$ of the patients of the previous study received WBI alone and no local therapy. And $70 \%$ of the patients in the previous study had a very poor performance score (3-4 according to the Eastern Cooperative Oncology Group, which is similar a KPS of $50 \%$ or less) (10). In the present study, only one patient had a KPS of $50 \%$ and no patient had a KPS of less than $50 \%$. Therefore, the aim to create a specific OS score particularly for patients receiving local therapies for a single lesion is justified. In the present study, two factors were included in the OS score, KPS and extracranial metastatic sites. Three prognostic groups were identified with significantly different OS rates at both 6 and 12 months. Of the patients of the 0-point group, no patient survived 6 months or longer. Therefore, these patients should receive the least stressful treatment possible, e.g. lower-dose (to keep the time patients have to lie under the tight head mask short) single-fraction stereotactic radiosurgery (e.g. 12$15 \mathrm{~Gy}$ ), or short-course local 3-D conformal radiotherapy (2). Neurosurgical resection should be avoided in this group. In the 1-point group and the 2-point group, $67 \%$ and $100 \%$ of the patients survived for 12 months or longer following treatment. Taking into account these favorable prognoses, improvement of intracerebral control and OS with acceptable late toxicity should be the goals of treatment. These patients appear suitable candidates for neurosurgical resection, higher-dose stereotactic radiosurgery (e.g. 20-25 Gy) or fractionated stereotactic radiotherapy (e.g. 3×10-12 Gy in three days), either alone or supplemented by WBI (19-22). However, taking into account the retrospective design of this study and the small size of the patient cohort, these recommendations are preliminary and await validation in a larger population.

In conclusion, given the limitations of the study, this very specific score can support physicians when they attempt to estimate the OS of patients planned to receive a local therapy for a single brain metastasis from a gynecological malignancy and can enhance the personalization of treatment for this particular patient group.

\section{Conflicts of Interest}

On behalf of all Authors, the corresponding Author states that there is no conflict of interest related to this study.

\section{References}

1 Siegel RL, Miller KD and Jemal A: Cancer statistics, 2017. CA Cancer J Clin 67: 7-30, 2017.

2 Tsao MN, Rades D, Wirth A, Lo SS, Danielson BL, Gaspar LE, Sperduto PW, Vogelbaum MA, Radawski JD, Wang JZ, Gillin MT, Mohideen N, Hahn CA and Chang EL: Radiotherapeutic and surgical management for newly diagnosed brain metastasis(es): An American Society for Radiation Oncology evidence-based guideline. Pract Radiat Oncol 2: 210-225, 2012. 
3 Sehmisch L, Schild SE and Rades D: Development of a survival score for patients with cerebral metastases from melanoma. Anticancer Res 37: 249-252, 2017.

4 Rades D, Dziggel L, Janssen S, Blanck O, Hornung D and Schild SE: A survival score for patients receiving stereotactic radiosurgery alone for brain metastases from breast cancer. Anticancer Res 36: 1073-1076, 2016.

5 Rades D, Bartscht T and Schild SE: Predictors of survival in patients with brain metastases from gastric cancer. Neoplasma 64: 136-139, 2017.

6 Rades D, Dziggel L, Hakim SG, Rudat V, Janssen S, Trang NT, Khoa MT and Bartscht T: Predicting survival after irradiation for brain metastases from head and neck cancer. In Vivo 29: 525528,2015

7 Rades D, Haatanen T, Schild SE and Dunst J: Dose escalation beyond 30 grays in 10 fractions for patients with multiple brain metastases. Cancer 110: 1345-1350, 2007.

8 Rades D, Evers JN, Veninga T, Stalpers LJ, Lohynska R and Schild SE: Shorter-course whole-brain radiotherapy for brain metastases in elderly patients. Int $\mathbf{J}$ Radiat Oncol Biol Phys 81 : e469-473, 2011.

9 Rades D, Dziggel L, Haatanen T, Veninga T, Lohynska R, Dunst $\mathrm{J}$ and Schild SE: Scoring systems to estimate intracerebral control and survival rates of patients irradiated for brain metastases. Int J Radiat Oncol Biol Phys 80: 1122-1127, 2011.

10 Rades D, Janssen S, Bajrovic A, Veninga T, Fischer D and Schild SE: A new scoring tool to assess overall survival in patients with intracerebral metastases from gynecological cancers. Int J Gynecol Cancer 27: 597-602, 2017.

11 Kaplan EL and Meier P: Non-parametric estimation from incomplete observations. J Am Stat Assoc 53: 457-481, 1958.

12 Lee HJ, Lee YH, Chong GO, Hong DG and Lee YS: Roboticassisted transperitoneal infrarenal para-aortic lymphadenectomy for gynecological malignancies: Comparison with a laparoscopic approach. Anticancer Res 37: 7087-7093, 2017.

13 Niibe Y, Onda T, Matsuo K, Inoue Y and Hayakawa K: Phase II study of concurrent chemoradiotheapy using nedaplatin for locally advanced uterine cervical carcinoma (KGROG0501): Final results. Anticancer Res 37: 6983-6988, 2017.

14 Tinelli G, Cappuccio S, Parente E, Fagotti A, Gallotta V, Conte C, Costantini B, Gueli Alletti S, Scambia G and Vizzielli G: Resectability and vascular management of retroperitoneal gynecological malignancies: A large single-institution caseseries. Anticancer Res 37: 6899-6906, 2017.
15 Koensgen D, Besic I, Gümbel D, Kaul A, Weiss M, Diesing K, Kramer A, Bekeschus S, Mustea A and Stope MB: Cold atmospheric plasma (CAP) and CAP-stimulated cell culture media suppress ovarian cancer cell growth - a putative treatment option in ovarian cancer therapy. Anticancer Res 37: 6739-6744, 2017.

16 Gadducci A and Guerrieri ME: Immune checkpoint inhibitors in gynecological cancers: Update of literature and perspectives of clinical tesearch. Anticancer Res 37: 5955-5965, 2017.

17 Bacalbasa N, Balescu I and Dima S: Rectosigmoidian involvement in advanced-stage ovarian cancer - intraoperative decisions. In Vivo 31: 973-977, 2017.

18 Watrowski R, Jäger $\mathrm{C}$ and Forster J: Improvement of perioperative outcomes in major gynecological and gynecologiconcological surgery with hemostatic gelatin-thrombin matrix. In Vivo 31: 251-258, 2017.

19 Chang EL, Wefel JS, Hess KR, Allen PK, Lang FF, Kornguth DG, Arbuckle RB, Swint JM, Shiu AS, Maor MH and Meyers CA: Neurocognition in patients with brain metastases treated with radiosurgery or radiosurgery plus whole-brain irradiation: a randomised controlled trial. Lancet Oncol 10: 1037-1044, 2009.

20 Brown PD, Jaeckle K, Ballman KV, Farace E, Cerhan JH, Anderson SK, Carrero XW, Barker FG 2nd, Deming R, Burri $\mathrm{SH}$, Ménard C, Chung C, Stieber VW, Pollock BE, Galanis E, Buckner JC and Asher AL: Effect of radiosurgery alone vs. radiosurgery with whole brain radiation therapy on cognitive function in patients with 1 to 3 brain metastases: A randomized clinical trial. JAMA 316: 401-409, 2016.

21 Aoyama H, Tago M, Kato N, Toyoda T, Kenjyo M, Hirota S, Shioura H, Inomata T, Kunieda E, Hayakawa K, Nakagawa K, Kobashi $\mathrm{G}$ and Shirato $\mathrm{H}$ : Neurocognitive function of patients with brain metastasis who received either whole brain radiotherapy plus stereotactic radiosurgery or radiosurgery alone. Int J Radiat Oncol Biol Phys 68: 1388-1395, 2007.

22 Huttenlocher S, Dziggel L, Hornung D, Blanck O, Schild SE and Rades D: A new prognostic instrument to predict the probability of developing new cerebral metastases after radiosurgery alone. Radiat Oncol 9: 215, 2014.

Received March 19, 2018

Revised March 30, 2018

Accepted April 2, 2018 